\section{A Study of the Morphological Process in Berom Language}

\author{
Marcus Pam Bitrus \\ Department of General Studies, Plateau State Polytechnic, Barkin Ladi \\ PMB 02023, Bukuru, Plateau State, Nigeria
}

Tel: 234-703-8274-702Ｅ-mail: proseque2000@yahoo.com

\author{
Dung Ishaya Pwajok (Corresponding author) \\ Department of General Studies, Plateau State Polytechnic, Barkin Ladi \\ PMB 02023, Bukuru, Plateau State, Nigeria
}

Tel: 234-803-288-3119

Pam Eric Ganan (Corresponding author)

Department of General Studies, Plateau State Polytechnic, Barkin Ladi

PMB 02023, Bukuru, Plateau State, Nigeria

Tel: 234-803-4419-153Ｅ-mail: ericpam2002@yahoo.com

Received: March 22, 2015 Accepted: May 27, 2015 Published: June 8, 2015

doi:10.5296/elr.v1i1.7774

URL: http://dx.doi.org/10.5296/elr.v1i1.7774

\begin{abstract}
This study presents a descriptive analysis of the Berom language morphological process. Data were sourced from related studies in Berom and other languages and from the intuitive knowledge of the writers who are native speakers of the language. Data analysis reveals that the morphological process in Berom is composed of affixation and compounding. The study also shows that the language has two inflectional prefixes: be- $\&$ n- that are used to mark plural noun and a derivational prefix: $\mathbf{n}$ - that is used for nominalization. Furthermore, the paper reveals that compounding in Berom can be simple or complex and asserts that simple compounding may generate a different word class while complex compounding realize nouns.
\end{abstract}

Keywords: Affixation, Berom, Compounding, Inflection, Morphology, Nominalize, Prefix 


\section{Introduction}

A lot of linguists have discussed morphological constructions in terms of process. Morphological process is any of the operations by which the forms of words are derived from their roots (Tomori, 2005; Grimes, 2005; Mathews, 1997). In langauges generally, new words can be derived from the root of existing words in any of the following processes: affixation, compounding, reduplication, clipping or suppletion. As far as the morphological process is concerned however, every language has its own system for the derivation of new words. In the view of Mathews (1997), of these morphological operations, the most widespread throughout the languages of the world is affixation.

\subsection{History and Geographical Location of Berom}

Although the history of the Berom people is still not very comprehensive, Pwajok (1991) posits that the Berom migrated from Egypt after an invasion and settled around Lake Chad before they arrived Nigeria and Plateau state. The meaning of the word Berom has always been linked with the name of the Berom mystical ancestors and the word designates the language and the ethnic group of the people. Gwom (1992) confirmed that the word Berom means the sent away. It is presumed that the founding fathers, who were either called worom or orom (a singular form of the speaker), migrated a very long time ago from old Gobir Empire of Sokoto state to Plateau State and settled in Kabong and Riyom villages where history has confirmed that their earliest men supposedly lived. Sansi (1980) also asserted that the tribe and speakers were called Shosho which was a nick name derived from Sho their conventional word for salutation. The Berom people have been described as a small but politically prominent people who live in central Nigeria (Gwom, 1992). Predominantly, the speakers are located in the core Jos Plateau and down the low plains of Kaduna State. With a population of over 500,000 speakers, the Berom language is spoken in parts of Plateau and Kaduna States (Gwom, 1992). The language was the predominant ethnic group in the former Jos division of Plateau State. With the division of the Jos province however, the Beroms are still significantly represented. In fact, a recent survey in the Plateau Times Magazine has confirmed that Berom is the largest single ethnic group in Plateau state and it is significantly represented in Jos North, and constitutes the majority in Jos South, Barkin Ladi and Riyom Local Government Arears.

Gwom (1992) distinguishes seven (7) intelligible dialects in Berom language; which are spoken in the eleven districts of Berom. These districts are: Bachi, Du, Fan, Foron, Gashish, Gyel, Heipan, Kuru, Ropp, Riyom and Vwang. This work is limited to the Du dialect of the Berom language and all words cited herein are from the dialect.

\subsection{Classification of Berom Language}

The Berom language has been classified under the family of Niger - Congo. In his classification of African Languages, Greenberg (1966) sub classified Berom as a member of the Benue - Congo of the Niger - Kordofanian phylum. The language has a very close affinity with the Bantu language group and shows some traces of the Niger-Congo affixes. Gwom (1992) states that the language has thirteen noun classes marked by prefixes which 


\section{Al Macrothink

conforms with the typical features of noun-class system of Bantu languages.

The Berom language strictly maintains a basic word-order of Subject - Verb - Object (SVO) throughout its grammar in main declarative sentences. This is confirmed in Pwajok (1987) and illustrated in the following sentence:

(a) Ma sei rugu.

\section{I / Agrsg TM buy/ shirt}

$\mathrm{S} \quad \mathrm{V} \quad \mathrm{O}$

I bought a shirt.

(b) Simi i kus ndok me.

Simi / Agrsg $\boldsymbol{T M}$ wash/ cloths her

$$
\text { S V O }
$$

Simi is washing her cloths.

\section{The Morphological Construction in Berom}

The morphological construction in Berom language involves two main processes: affixation $\&$ compounding. Within these processes, each has been subcategorized as shown in Figure 1 below.

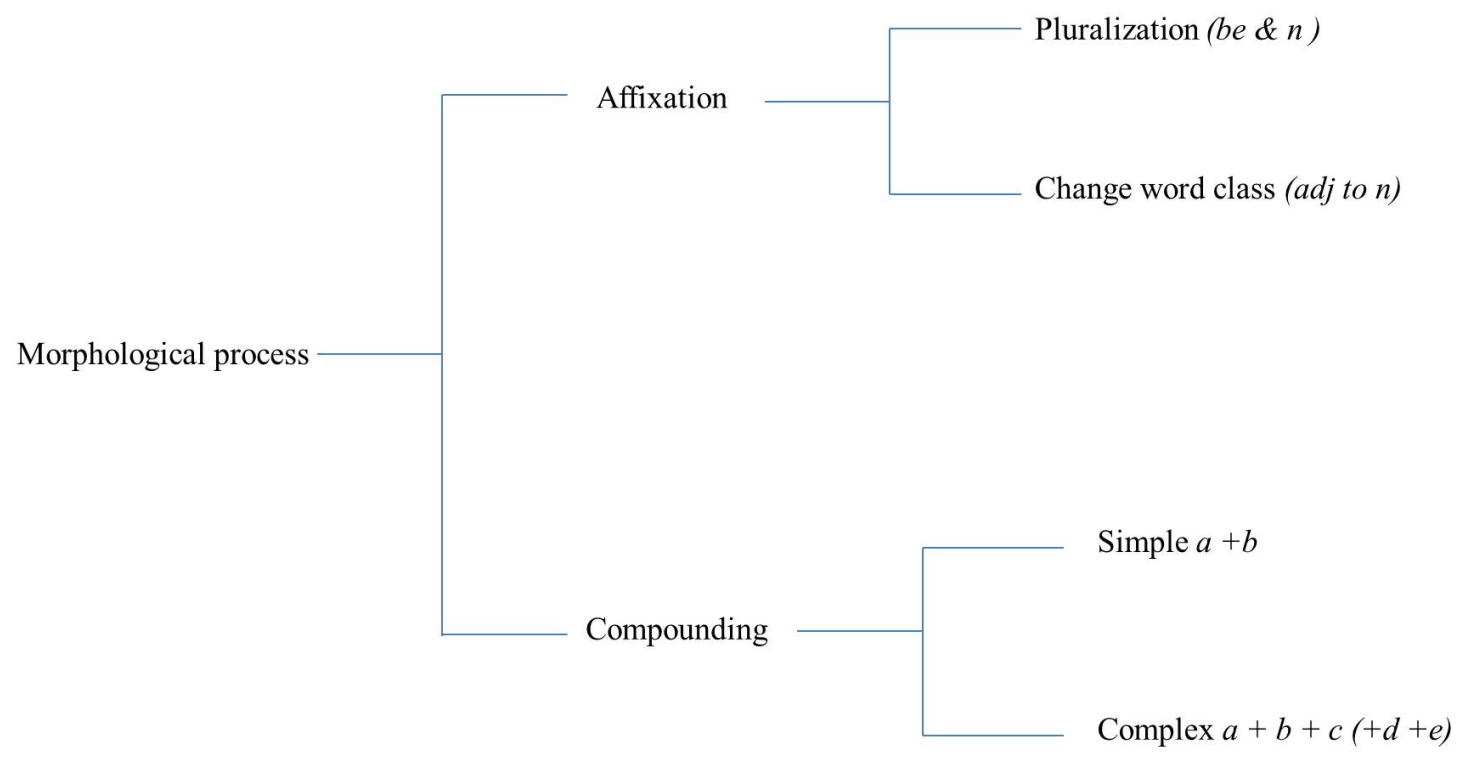

Figure 1. Morphological Construction in Berom 


\section{Macrothink \\ Education and Linguistics Research \\ ISSN 2377-1356 2015, Vol. 1, No. 1}

\subsection{Affixation}

From Figure 1 above, the Berom language operates only one type of affixation which is prefixation. This shows that other processes of word formation like suffixation that is found in English are not applicable in Berom. Thus, the scheme for affixation in Berom has been provided in Figure 2 below:

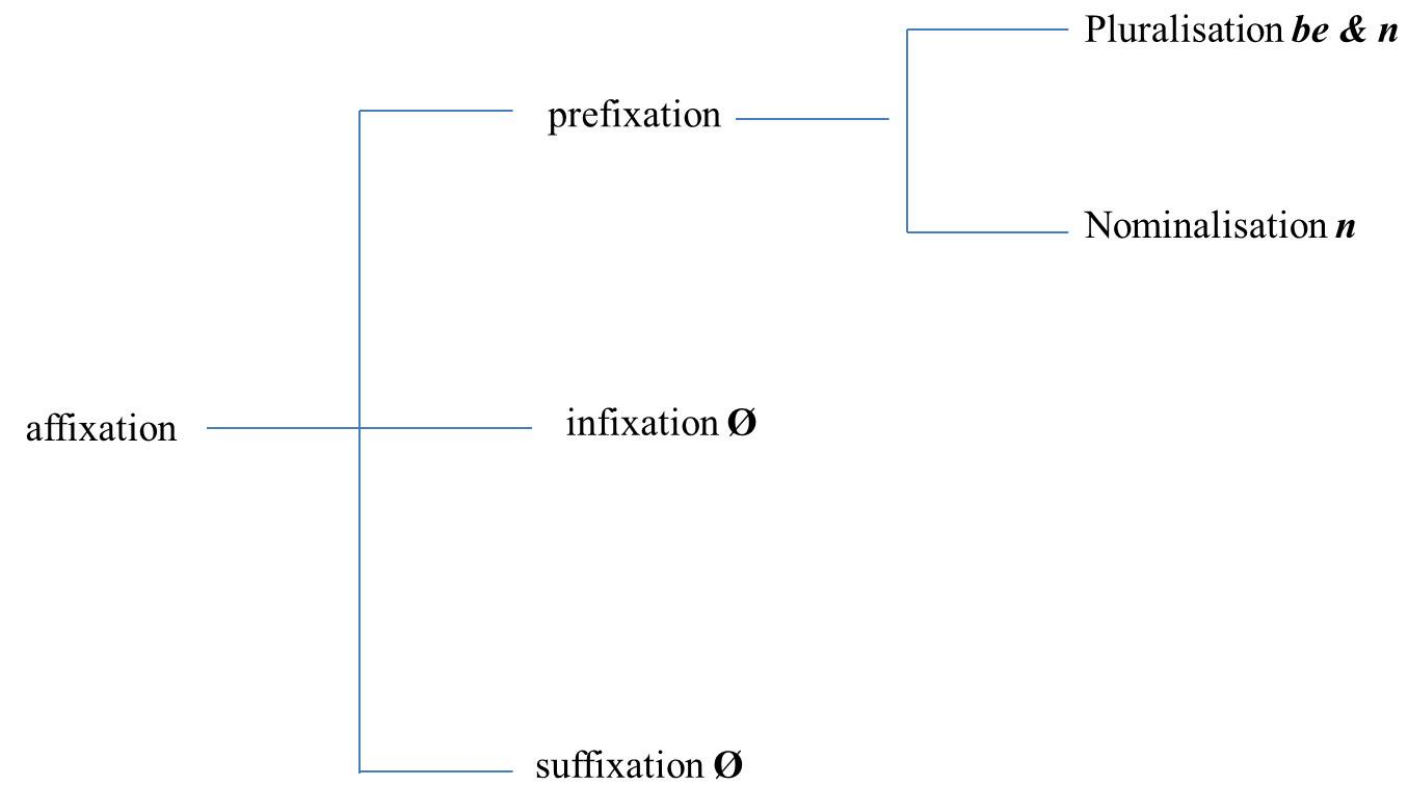

Figure 2. Affixation in Berom

From Figure 2 above, prefixation is the only process of affixation that exists in Berom langauge. Furthermore, 2 segments $\boldsymbol{n}$ - and $\boldsymbol{b} \boldsymbol{e}$ - are placed before nouns to generate new words. While the segements $\boldsymbol{n}$ - and $\boldsymbol{b} \boldsymbol{e}$ - are used as inflections to mark plural, $\boldsymbol{n}$ - is used to change the word class of adjectives to nouns as shown in the following:

\subsection{1 $\boldsymbol{n}+$ noun to Mark Plural}

The segment $n$ - pluralizes a certain category of nouns that are concrate or abstract when it is prefixed to them as shown in the following examples:
a) shi
$\rightarrow$ nshi
plate
plates
b) shwe $\rightarrow$ nshwe
sense
senses 


\begin{tabular}{|c|c|c|}
\hline $\mathrm{mi}$ & $\rightarrow$ & nmi \\
\hline blood & & blood (quantified) \\
\hline lo & $\rightarrow$ & nlo \\
\hline house & & houses \\
\hline
\end{tabular}

Note: The concrate nouns in this category can either be countable or uncountable.

\subsection{2 $\boldsymbol{b} \boldsymbol{e}+$ Noun to Mark Plural}

As a plural marker, the morpheme be- attaches with only nouns that are said to be concrate and countable as shown below:
a) gwa $\rightarrow$ begwa
brother brothers
b) yis $\quad \rightarrow$ beyis
eye eyes
c) nen $\rightarrow$ benen
$\sin \quad \operatorname{sins}$
d) zal $\rightarrow$ bezal
ridge ridges
e) val $\rightarrow$ beval
breast breasts
f) yin $\rightarrow$ beyin
tooth teeth

Note: the segment $\boldsymbol{b} \boldsymbol{e}$ - can not be merged with abstract or uncountable nouns to mark their plural. 


\section{Macrothink \\ Education and Linguistics Research \\ ISSN 2377-1356 2015, Vol. 1, No. 1}

\subsection{3 $\boldsymbol{n}+$ Adjective to Nominalize Adjectives}

Unlike in 2.1.1 above where the nasal prefix $n$ - marks the plural of certain category of nouns, the morpheme $n$ - changes the word class of a segment in this section. The segment $n$ nominalizes adjectives as examplified in the sentences below:

a. tong (fool)

$\rightarrow$ ntong (foolishnes)

Somoa si tong

Your son is a fool.

A duna ntong me i nuyel bemwad

He displayed his foolishness before the crowd.

b. ta (sweet)

$\rightarrow$ nta (enjoyment)

Pyei mwo a ta.

The food is sweet.

Mi wok ki nta hwong i lama lo.

I am having a little enjoyment behind the house.

c. tyang (well)

$\rightarrow$ ntyang (well- being)

Yini pwol tyang a.

Did you (pl) sleep well?

In ma ra bwol mwo mi kys se

If I follow your steps, my well-being will ntyang. improve.

\section{Compounding}

Basically, a large number of Berom words are morphologically derived through compounding. Compounding in Berom can be simple or complex. Simple compounding in Berom is categorized into nine while complex compounding is categorized into five.

\subsection{Simple Compounding}

Simple compounding in Berom requires the combination of two words from separate word classes. Two of these grammatical classes: noun and verb; however allow the combination of words from within the same class. From the structure in Figure (1) above the combination of the word categories can generate the following words:

\subsubsection{Noun + Adjective}

Noun and adjective are combined in that order to generate new word but the meaning of the derived word is not realized from the combination of the independent words. The descriptive function of the adjective shifts to connotation as shown in the following: 

a. yei + pyeng $\rightarrow$ yeipyeng
heart white $\rightarrow$ joy
b. polo + lis $\rightarrow$ pololis
day $\quad$ long $\rightarrow$ long life
c. bwol + pyeng $\rightarrow$ bwolpyeng
leg $\quad$ white $\rightarrow$ superstitious
d. yei $\quad+$ tsiru $\rightarrow$ yeitsiru
heart black $\rightarrow$ saddist

(Pwajok, 1991)

\subsubsection{Noun + Noun}

Two lexical nouns in Berom are conjoined to form a new root. Compounded words in this category are mostly nouns that are abscribed to human beings and their institutions. When an animate noun appears as the first noun, the derived word exhibits no semantic change from the independent meanings of the nouns. But when the preceeding noun is inanimate, the meaning of the realized word does not reflect the combined words as shown in the following:
a. ngo
+ hei
$\rightarrow$ ngohei
mother
bush
farmer (female)
b. da
$+\mathbf{l b}$
$\rightarrow$ dalo
head
home
breadwinner (male)
c. fwa
+ dyam
$\rightarrow$ fwadyam
stone
money
wealthy
d. hwai
+ gul
$\rightarrow$ hwaigul
son
breeze
wayward son/ bastard
e. lo
+ basa
$\rightarrow$ lobasa 

home
read
school
f. hwa
+ lo
$\rightarrow$ hwals
woman
home
housewife
g. gwom
+ shot
$\rightarrow$ gwomshot
chief
case
judge
h. nta
+ yei
$\rightarrow$ ntayei
enjoyment heart
sweetheart
i. nta
+ gwi
$\rightarrow$ ntagwi
enjoyment
firmament (heaven)
God's joy

\subsubsection{Verb + Noun}

In this group, active verbs are conjoined with concrate nouns to generate new words. In most cases the meaning of the realized word is not a reflection of the independent meanings of the combined words as shown below:
a. wuna + to $\rightarrow$ wunato
join head unite
b. rangas + gwi $\rightarrow$ rangasgwi
burn sun dream
c. tes + to $\rightarrow$ testto
hit head to practice islam
d. di $\quad+$ lo $\rightarrow$ dilo
see house a traditional wedding rite

\subsubsection{Noun + Verb}

A combination of these categories of words naturally has the meaning of the independent words embedded in the meaning of the derived word as depicted in the following: 

a. nu $\quad+$ ha $\rightarrow$ nuha
mouth talk opinion
b. bwok + basa $\rightarrow$ bwokbasa
book read textbook
c. hwong + yom $\rightarrow$ hwongyom
girl stress impoverished girl
d. ngo + yom $\rightarrow$ ngoyom
mother stress impoverished woman

\subsubsection{Verb + Verb}

This is an exceptional case of word formation in Berom. It is exceptional in the sense that when the two verbs are brought together the end result is a nominal term as examplified below:

$$
\begin{array}{rrr}
\text { a. } & \text { rei }+ \text { yəm } & \text { reiyəm } \\
\text { eat } & \text { stress } & \text { poverty }
\end{array}
$$

\subsubsection{Verb + Preposition}

The Berom verb rei combines with a few categories of prepositions to generate words and the realized words maintain a verbal status as seen in the following:
a. rei + jei $\rightarrow$ reijei
eat flirt
b. rei + nuyel $\rightarrow$ reinuyel
eat ahead progress
c. rei + lama $\rightarrow$ reilama
eat behind regress

\subsubsection{Noun + Preposition}




\section{Macrothink \\ Education and Linguistics Research \\ ISSN 2377-1356 2015, Vol. 1, No. 1}

The noun + preposition combination is one of the processes of nominalization in Berom. This word class combination is very rare as indictaed in the example below:
a. da + manjei $\rightarrow$ damanjei
head outside ward leader

\subsubsection{Pronoun + Preposition}

In this category, the Berom pronoun mwad combines with the preposition to form a new word and the product of the derived word changes to a noun as examplified below:

a. mwad + nuyel $\rightarrow$ mwadnuyel
someone $\quad$ ahead $\quad$ leader

\subsubsection{Pronoun + Verb}

Here, the Berom pronoun mwad combines with only active verbs to generate new words. Thus, the merging of the pronoun $m w a d$ with an action verb nominalizes the verb as revealed in the following examples from Sansi, 1980:
a. mwad + tolo $\rightarrow$ mwadtolo
someone sew tailor
b. mwad + jek $\rightarrow$ mwad jek
someone write secretary
c. mwad + ra $\rightarrow$ mwadra
someone follow believer
d. mwad + testo $\rightarrow$ mwadtesto
someone hit head muslim
e. mwad + sele $\rightarrow$ mwadsele
someone help helper

\subsection{Complex Compounding}

In Berom, complex compounding has the same syntactic and semantic behaviour of a noun 


\section{Macrothink}

and they are all formed with an overt imperative subject and verb. Consequently, we have identified five sentential compound formations in Berom which are examplified below:

3.2.1 N+N+ N+V+N Formation

This formation is composed of a combination of four nouns and a verb in order to realize a new word. The derived word turns out to be a noun as indicated by the English noun mosque below:

$$
\begin{aligned}
& \text { duk }+ \text { wusal } \\
& \text { room } \quad \text { bemwad }+ \text { tes }+ \text { to } \rightarrow \text { mosque } \\
& \text { fellowship } \quad \text { people } \text { hit head }
\end{aligned}
$$

3.2.2 $\mathrm{N}+\mathrm{N}+\mathrm{N}+\mathrm{V}$ Formation

In this category, three nouns are conjoined with a verb to create a new word. The English word church has been used below to explain how this is realized in Berom.

duk + wusal + bemwad + ra $\rightarrow$ church
room fellowship people follow

\subsection{3 $\mathrm{N}+\mathrm{V}+\mathrm{N}+\mathrm{N}$ Formation}

Here, the verbal item appears amist three nouns as shown below:

$$
\begin{aligned}
& \text { bwok }+ \text { basa }+ \text { da }+ \text { gwi } \rightarrow \text { bible } \\
& \text { book } \quad \text { read head heaven }
\end{aligned}
$$

\subsubsection{N + N + V Formation}

In this formatiom, a new word is generated as a result of the merging of two nouns and a verb.

$$
\begin{aligned}
& \text { mwad }+ \text { gufa }+ \text { sangal } \rightarrow \text { head } \\
& \text { someone } \quad \text { stone } \quad \text { sit }
\end{aligned}
$$

\subsubsection{N+V+ N+V+ N Formation}

This type is composed of three nouns and two verbs which are merged to form a noun based word as shown below:

$$
\text { bwok }+ \text { basa }+ \text { bemwad }+ \text { tes to } \rightarrow \text { koran }
$$


book read people hit head

\section{Conclusion}

The morphological process of Berom is composed of affixation and compounding. Two inflectional prefixes: $\boldsymbol{b} \boldsymbol{e}$ - and $\boldsymbol{n}$ - are used to generate plural nouns while as a derivational prefix, the segment $\boldsymbol{n}$ - changes the class of words from adjective to noun. Compounding in Berom is simple and complex. From the data we presented and analyzed in this study, we have concluded that simple compounding has the following structure: $\mathrm{N}+\mathrm{N}, \mathrm{N}+\mathrm{Adj}, \mathrm{N}+\mathrm{V}, \mathrm{N}+$ $\mathrm{PP}, \mathrm{V}+\mathrm{N}, \mathrm{V}+\mathrm{V}, \mathrm{V}+\mathrm{PP}$, Prn $+\mathrm{PP}$, Prn $+\mathrm{V}$ while complex compounding is a composition of a string of nouns and a verb. Also, while the derived word in simple compounding may take the word class of either of the merged-words or assumes a different word class the derived words in complex compounding however, assume the word class status of a noun.

\section{References}

Berom, R. A Publication of Berom Students, University of Jos, Nigeria (2nd Ed).

Blench, R. (2006). Adjective Morphology in Eastern Berom. http:/www.rogerblench.info/RBOP.htm

Dustan, E. (1969). Twelve Nigerian Languages. Longmans.

Galadanci, M. K. M. (1976). An introduction to Hausa Grammar. Longman Nigeria Ltd.

Greenberg, J. (1966). The language of Africa. The Hague.

Grimes, B. F. (2005). Ethnologue: Language of the world. Sil, Dallas.

Gwom, S. L. (1983). History of Jos and Political Development. Jos: Jos University Press.

Gwom, S. L. (1992). The Berom Tribe of Plateau State of Nigeria. Jos: Fab Anieh Nigeria Limited.

Johnpaul, O. N. (2013). A Structural Analysis of Igala Verb Phrase. Presented at the Joint Conference of the West Africa Linguistic Society (WALS) and Linguistics Association of Nigeria(LAN). University of Ibadan, Ibadan, Nigeria, July 29- August 3.

Marcus, P. B., Umar, N. S., \& Pam, E. G. (2013). An Analysis of the Berom Verb Phrase: A Minimalist Approach. Presented at the Joint Conference of the West Africa Linguistic Society(WALS) and Linguistics Association of Nigeria(LAN). University of Ibadan, Ibadan, Nigeria. July 29-August 3.

Mathews, P. H. (1993). Morphology. London Cambridge University Press.

Ngaidandi, N. (2011). The Morphology of Nouns in Tupuri Language of Chad. M.A. Seminar Paper (Unpublished) University of Maiduguri.

Omachonu, G. S. (2008). Inflectional Morphology: A Study of Grammatical Categories in Igala. Journal of the Linguistics Association of Nigeria, 11, 33-40 


\section{Macrothink

Pwajok, O. E. (1987). A Short Grammer of Berom. B.A. Project (unpublished), Department of Languages and Linguistics, University of Jos.

Sansi, O. O. (1980). "Contrasive Analysis of the sound systems of the Berom and the English Language”. B. A. Project, University of Jos.

Suffil, T. L. (1968). Lele Berom. Lagos: Associated Press of Nigeria.

The Plateau Times Magazine. Maiden Edition. Vol. 1 No. 1 April 2005

Tomori, S. H. O. (1997). The Morpholgy and Syntax of present day English: an introduction. London: Heinemann Educational Books Ltd.

\section{Copyright Disclaimer}

Copyright reserved by the author(s).

This article is an open-access article distributed under the terms and conditions of the Creative Commons Attribution license (http://creativecommons.org/licenses/by/3.0/). 